\title{
Furosemide/Non-Steroidal Anti-Inflammatory Drug-Drug Pharmaceutical Solids: Novel Opportunities in Drug Formulation
}

\author{
Francisco Javier Acebedo-Martínez ${ }^{1}$, Carolina Alarcón-Payer ${ }^{2}$, Lucía Rodríguez-Domingo ${ }^{1,3}$, \\ Alicia Domínguez-Martín ${ }^{3}\left[{ }^{(1)}\right.$, Jaime Gómez-Morales ${ }^{1}$ (1) and Duane Choquesillo-Lazarte ${ }^{1, *}$ \\ 1 Laboratorio de Estudios Cristalográficos, IACT, CSIC-Universidad de Granada, Avda. de las Palmeras 4, \\ 18100 Armilla, Spain; j.acebedo@csic.es (F.J.A.-M.); luciard13@hotmail.com (L.R.-D.); \\ jaime@lec.csic.es (J.G.-M.) \\ 2 Servicio de Farmacia, Hospital Universitario Virgen de las Nieves, 18014 Granada, Spain; \\ carolina.alarconpayer@gmail.com \\ 3 Department of Inorganic Chemistry, Faculty of Pharmacy, University of Granada, 18071 Granada, Spain; \\ adominguez@ugr.es \\ * Correspondence: duane.choquesillo@csic.es
}

check for updates

Citation: Acebedo-Martínez, F.J.; Alarcón-Payer, C.; RodríguezDomingo, L.; Domínguez-Martín, A.; Gómez-Morales, J.; ChoquesilloLazarte, D. Furosemide/NonSteroidal Anti-Inflammatory Drug-Drug Pharmaceutical Solids: Novel Opportunities in Drug Formulation. Crystals 2021, 11, 1339 https://doi.org/10.3390/ cryst11111339

Academic Editor: Aidar T. Gubaidullin

Received: 18 October 2021

Accepted: 31 October 2021

Published: 2 November 2021

Publisher's Note: MDPI stays neutral with regard to jurisdictional claims in published maps and institutional affiliations.

Copyright: (c) 2021 by the authors. Licensee MDPI, Basel, Switzerland. This article is an open access article distributed under the terms and conditions of the Creative Commons Attribution (CC BY) license (https:// creativecommons.org/licenses/by/ $4.0 /)$.

\begin{abstract}
The design of drug-drug multicomponent pharmaceutical solids is one the latest drug development approaches in the pharmaceutical industry. Its purpose is to modulate the physicochemical properties of active pharmaceutical ingredients (APIs), most of them already existing in the market, achieving improved bioavailability properties, especially on oral administration drugs. In this work, our efforts are focused on the mechanochemical synthesis and thorough solid-state characterization of two drug-drug cocrystals involving furosemide and two different non-steroidal anti-inflammatory drugs (NSAIDs) commonly prescribed together: ethenzamide and piroxicam. Besides powder and single crystal X-ray diffraction, infrared spectroscopy and thermal analysis, stability, and solubility tests were performed on the new solid materials. The aim of this work was evaluating the physicochemical properties of such APIs in the new formulation, which revealed a solubility improvement regarding the NSAIDs but not in furosemide. Further studies need to be carried out to evaluate the drug-drug interaction in the novel multicomponent solids, looking for potential novel therapeutic alternatives.
\end{abstract}

Keywords: drug-drug cocrystal; furosemide; ethenzamide; piroxicam; mechanochemical synthesis

\section{Introduction}

Diuretic drugs aim to regulate the volume and composition of body fluids by increasing the rate of urine flow and sodium excretion. They are widely used in clinics for the treatment of edematous disorders, such as those associated with congestive heart failure, as well as liver or renal failure and hypertension [1,2]. Furosemide (FUR, Scheme 1), 4-chloro2-[(2-furanylmethyl)-amino]-5-sulfamoylbenzoic acid, is classified as a high ceiling loop diuretic drug. Its mechanism of action is related to the inhibition of the sodium-potassium2chloride co-transporter $\left(\mathrm{Na}^{+}-\mathrm{K}^{+}-2 \mathrm{Cl}^{-}\right)$located in the thick ascending limb of the loop of Henle in the renal tubule.

According to the Biopharmaceutics Classification System (BCS), FUR belongs to class IV drug, defined by low solubility and low permeability values [3]. Indeed, furosemide is almost insoluble in water [4], which results in significant intraindividual variations in absorption and very poor oral bioavailability [5]. Despite this relevant drawback, FUR has shown great efficacy, hence it is highly used in therapeutics worldwide, including chronic treatments. Thereby, the development of improved oral formulations of furosemide, which aim to achieve higher bioavailability, are certainly relevant for the pharmaceutical industry.

The design of multicomponent pharmaceutical solids is actually one of the latest research strategies in the development of new drug alternatives in the pharmaceutical 
industry [6]. They can be defined as crystalline materials in which at least one component is an active pharmaceutical ingredient (API). The other components, incorporated in the crystal lattice-so-called coformers-must be found in a stoichiometric ratio and considered pharmaceutically acceptable-i.e., included in the Generally Recognized as Safe (GRAS) list within the FDA's "Substances Added to Food" Inventory. APIs and coformers recognize themselves by different kind of non-covalent intermolecular interactions, so-called supramolecular synthons, mainly $\mathrm{H}$-bonds, which organization has a profound impact on the intimate 3D structure of the solid and therefore on its macroscopic physicochemical properties. The development of this novel strategy is rather interesting because allows industry to save money compared to the traditional drug development scheme, still guarantying the possibility of generating intellectual property rights [7]. In this context, there has been reported several studies devoted to studying pharmaceutical cocrystals and salts of furosemide [8-13].<smiles>NS(=O)(=O)c1cc(C(=O)O)c(NCc2ccco2)cc1Cl</smiles>

Furosemide, FUR<smiles>CCOc1ccccc1C(N)=O</smiles>

Ethenzamide, ETZ<smiles>CN1C(C(=O)Nc2ccccn2)=C(O)c2ccccc2S1(=O)=O</smiles>

Piroxicam, PRX

Scheme 1. Chemical formula of furosemide (FUR), ethenzamide (ETZ), and piroxicam (PRX).

One of the most recent approaches in the development of multicomponent pharmaceutical solids is the concurrent administration of two or more APIs, leading to drug-drug or co-drug pharmaceutical solids [14]. APIs within the formulation might have similar or different mechanisms of actions, but always looking for a synergic effect, either targeting one metabolic pathway at different levels or different pathways related to a particular disease.

Along with diuretics, nonsteroidal anti-inflammatory drugs (NSAIDs) are also widely prescribed worldwide. Interestingly, the combination of diuretics - particularly furosemide - and NSAIDs is rather common, especially among the elderly. However, although not contraindicated, there is clinical evidence on the moderate interaction between these two kinds of drugs. The use of NSAIDs may decrease natriuretic response to loop diuretics, thus reducing their efficacy and resulting in adverse effects on patients with different edematous states. In addition, some NSAIDs may also show adverse nephrotoxic effects, which may be exacerbated by diuretic therapy [15-17]. In these cases, dose adjustments or special monitoring of the renal function and blood pressure are required for safety's sake. Unfortunately, the insights of such interactions are still poorly understood because they do not seem to follow the same mechanism for all combination of drugs, some of them being associated with the suppression of plasma renin activity or impaired synthesis of vasodilator prostaglandins.

Since the concurrent prescription of FUR and NSAIDs is quite common, it is worthwhile exploring the formulation of drug-drug multicomponent pharmaceutical solids involving such a combination, seeking new therapeutical alternatives that would improve the bioavailability of the APIs and/or reduce the abovementioned drug-drug interactions. In this work, the synthesis and physicochemical characterization of two different drugdrug pharmaceutical solids, including the loop diuretic furosemide and one NSAID drug: ethenzamide (ETZ, 2-ethoxybenzamide) or piroxicam (PRX, 4-hydroxyl-2- methyl-N-2pyridinyl-2H-1,2,-benzothiazine-3-carboxamide 1,1-dioxide) are reported (Scheme 1). To the best of our knowledge, there are no conclusive studies on the interaction between furosemide and ethenzamide, while one study was reported on piroxicam-furosemide drug interaction in the late 1980s [18]. 


\section{Materials and Methods}

\subsection{Materials}

Furosemide, ethenzamide, piroxicam, and solvents used are commercially available from Sigma-Aldrich. All solvents were used as received without additional purification.

\subsection{Coformer Selection}

A search of the Cambridge Structural Database (CSD) [19] was conducted to identify the coformers with complementary functional groups that can serve as components for molecular recognition with FUR.

The excess enthalpy $\left(\mathrm{H}_{\mathrm{ex}}\right)$ of mixing between FUR and selected coformers was calculated using COSMOquick software [20] (COSMOlogic, Germany, Version 1.4).

\subsection{General Procedure for Mechanochemical Synthesis}

Mechanochemical syntheses of cocrystals were conducted by liquid-assisted grinding (LAG) in a Retsch MM200 ball mill (Retsch, Haan, Germany) operating at $25 \mathrm{~Hz}$ frequency using stainless steel jars along with stainless steel balls of $7 \mathrm{~mm}$ diameter. All syntheses were repeated to ensure reproducibility. For liquid-assisted grinding screening, methanol was used as solvent.

Synthesis of FUR-ETZ: a mixture of FUR ( $165.37 \mathrm{mg}, 0.50 \mathrm{mmol})$ and ETZ (82.59 mg, $0.50 \mathrm{mmol}$ ) in a 1:1 stoichiometric ratio was placed in a $10 \mathrm{~mL}$ stainless steel jar along with $150.0 \mu \mathrm{L}$ of methanol and two stainless steel balls of $7 \mathrm{~mm}$ diameter. The mixture was then milled for $30 \mathrm{~min}$.

Synthesis of FUR-PRX: a mixture of FUR $(165.37 \mathrm{mg}, 0.50 \mathrm{mmol})$ and PRX (165.67 mg, $0.50 \mathrm{mmol}$ ) in a 1:1 stoichiometric ratio was placed in a $10 \mathrm{~mL}$ stainless steel jar along with $150.0 \mu \mathrm{L}$ of methanol and two stainless steel balls $7 \mathrm{~mm}$ in diameter. The mixture was then milled for $30 \mathrm{~min}$.

\subsection{Powder X-ray Diffraction (PXRD)}

Powder X-ray diffraction data were collected using a Bruker D8 Advance V $\alpha$ rio diffractometer (Bruker-AXS, Karlsruhe, Germany) equipped with a LYNXEYE detector and $\mathrm{Cu}-\mathrm{K} \alpha 1$ radiation $(1.5406 \AA)$. All the profile fittings were conducted using the software Diffrac.TOPAS 6.0 [21]. The bulk phase purity was checked by Le Bail profile fitting, using cell parameters from structural crystallographic information of the constitutive phases—namely FUR, ETZ, and PRX—as well as the new reported phases. In these fittings, only the background, unit cell parameters and zero error were refined. Rwp values obtained in all cases demonstrate an excellent agreement between the structural model and the bulk phase measured by powder diffraction.

\subsection{Preparation of Single Crystals}

Single crystals were grown by solvent evaporation at room temperature using the polycrystalline material obtained from mechanical synthesis. Suitable crystals for X-ray diffraction studies were obtained from recrystallization in saturated solutions after approximately 2 days: methanol and acetone for FUR-ETZ and ethanol for FUR-PRX.

\subsection{Single-Crystal X-ray Diffraction (SCXRD)}

Measured crystals were prepared under inert conditions immersed in perfluoropolyether as protecting oil for manipulation. Suitable crystals were mounted on MiTeGen Micromounts $^{\mathrm{TM}}$ (MiTeGen, Ithaca, NY, USA), and these samples were used for data collection. Data for FUR-ETZ and FUR-PRX were collected with a Bruker D8 Venture diffractometer (Bruker-AXS, Karlsruhe, Germany) with graphite monochromated MoK $\alpha$ (FUR-ETZ, $\lambda=0.71073 \AA$, at 298(2) K) or CuK $\alpha$ radiation (FUR-PRX, $\lambda=1.54178 \AA$, at 298(2) K). The data were processed with APEX3 suite [22]. The structures were solved by Intrinsic Phasing using the ShelXT program [23], which revealed the position of all non-hydrogen atoms. These atoms were refined on $\mathrm{F}^{2}$ by a full-matrix least-squares procedure using 
anisotropic displacement parameter [24]. All hydrogen atoms were located in difference Fourier maps and included as fixed contributions riding on attached atoms with isotropic thermal displacement parameters 1.2- or 1.5-times those of the respective atom. The OLEX2 software was used as a graphical interface [25]. Intermolecular interactions were calculated using PLATON [26]. Molecular graphics were generated using Mercury [27]. The crystallographic data for the reported structures were deposited with the Cambridge Crystallographic Data Center as supplementary publication No. CCDC 2114160 and 2114161. Additional crystal data are shown in Table 1. Copies of the data can be obtained free of charge at http:/ / www.ccdc.cam.ac.uk/products/csd/request (accessed on 30 October 2021).

Table 1. Crystallographic data and structure refinement details of FUR cocrystals.

\begin{tabular}{|c|c|c|}
\hline Compound Name & FUR-ETZ & FUR-PRX \\
\hline Formula & $\mathrm{C}_{21} \mathrm{H}_{22} \mathrm{ClN}_{3} \mathrm{O}_{7} \mathrm{~S}$ & $\mathrm{C}_{27} \mathrm{H}_{24} \mathrm{ClN}_{5} \mathrm{O}_{9} \mathrm{~S}_{2}$ \\
\hline Formula weight & 495.92 & 662.08 \\
\hline Crystal system & Monoclinic & Monoclinic \\
\hline Space group & $P 2_{1} / c$ & $P 2_{1} / n$ \\
\hline $\mathrm{a} / \AA$ & $13.1846(4)$ & $9.0971(4)$ \\
\hline $\mathrm{b} / \AA$ & $9.8733(3)$ & $23.8637(10)$ \\
\hline$c / \AA$ & $17.1518(6)$ & $13.7806(6)$ \\
\hline$\alpha /^{\circ}$ & 90 & 90 \\
\hline$\beta /{ }^{\circ}$ & $95.776(2)$ & $99.227(2)$ \\
\hline$\gamma /{ }^{\circ}$ & 90 & 90 \\
\hline $\mathrm{V} / \AA^{3}$ & $2221.41(12)$ & $2952.9(2)$ \\
\hline Z & 4 & 4 \\
\hline $\mathrm{D}_{\mathrm{c}} / \mathrm{g} \mathrm{cm}^{-3}$ & 1.483 & 1.489 \\
\hline$\mu / \mathrm{mm}^{-1}$ & 0.315 & 3.010 \\
\hline $\mathrm{F}(000)$ & 1032 & 1368 \\
\hline Reflections collected & 32,492 & 41,427 \\
\hline Unique reflections & 5104 & 5172 \\
\hline $\mathrm{R}_{\text {int }}$ & 0.1392 & 0.0331 \\
\hline Data/restraints/parameters & $5104 / 0 / 305$ & $5172 / 0 / 406$ \\
\hline Goodness-of-fit $\left(\mathrm{F}^{2}\right)$ & 1.002 & 1.032 \\
\hline$R 1(\mathrm{I}>2 \sigma(\mathrm{I}))$ & 0.0584 & 0.0379 \\
\hline$w \mathrm{R} 2(\mathrm{I}>2 \sigma(\mathrm{I}))$ & 0.1054 & 0.0959 \\
\hline Packing coefficient & 0.69 & 0.67 \\
\hline
\end{tabular}

\subsection{Stability Test}

Slurry experiments were conducted using excess powder samples of each phase in $1 \mathrm{~mL}$ of water for $24 \mathrm{~h}$ at room temperature in a sealed vial containing a magnetic stirrer. The solids in the vials were collected, filtered, and dried at $35^{\circ} \mathrm{C}$ for subsequent analysis by PXRD.

Stability of all the new phases was also studied at accelerated storage condition; $200 \mathrm{mg}$ of each solid was taken in watch glasses and the physical stability was evaluated at $40{ }^{\circ} \mathrm{C}$ in $75 \%$ relative humidity using a Memmert HPP110 climate chamber (Memmert, Schwabach, Germany). The samples were subjected to the above accelerated stability conditions for 3 days and weekly intervals from 1 week to 8 weeks. PXRD was used to monitor the stability of the solid forms.

\subsection{Infrared Spectroscopy}

Fourier-transform infrared (FTIR) spectroscopic measurements were performed on a Bruker Tensor 27 FTIR instrument (Bruker Corporation, Billerica, MA, USA) equipped with a single-reflection diamond crystal platinum ATR unit and OPUS data collection program. The scanning range was from 4000 to $400 \mathrm{~cm}^{-1}$ with a resolution of $4 \mathrm{~cm}^{-1}$. 


\subsection{Thermal Analysis}

Simultaneous thermogravimetric analysis (TGA) and differential scanning calorimetry (DSC) measurements were performed using a Mettler Toledo TGA/DSC1 thermal analyzer (Mettler Toledo, Columbus, OH, USA). Samples (3-5 mg) were placed into sealed aluminum pans and heated in a stream of nitrogen $\left(100 \mathrm{~mL} \mathrm{~min}^{-1}\right)$ from 25 to $400{ }^{\circ} \mathrm{C}$ at a heating rate of $10{ }^{\circ} \mathrm{C} \min ^{-1}$.

\subsection{Solubility Studies}

Solubility studies for pure FUR and each new cocrystal were performed using the Crystal16 equipment (Technobis Crystallization Systems, Alkmaar, The Netherlands) in water PBS at pH 7.4. The equipment is comprised of four individually controlled reactors, each with a working volume of $1 \mathrm{~mL}$, allowing the measurement of cloud and clear points based on the turbidity of 16 aliquots of $1 \mathrm{~mL}$ of solution in parallel and automatically. Each composition was heated at $0.5^{\circ} \mathrm{C} / \mathrm{min}$ to $90^{\circ} \mathrm{C}$ with a magnetic stirring rate of $700 \mathrm{rpm}$, held at this temperature for $10 \mathrm{~min}$ and then cooled to $20^{\circ} \mathrm{C}$ at $0.5^{\circ} \mathrm{C} / \mathrm{min}$. The temperature of dissolution for each compound was measured using different amounts of solid, and the solubility data of the pure components were fitted to the Van't Hoff equation [28] using the CrystalClear software (Technobis Crystallization Systems, Alkmaar, The Netherlands).

\section{Results and Discussion}

\subsection{Coformer Selection}

Before the experimental trials, we performed virtual cocrystal screening to improve the success rate. A survey on the Cambridge Structural Database (CSD version 5.42, update 2 from May 2021) based on FUR resulted in 70 hits. After excluding datasets corresponding to FUR polymorphs, the remaining dataset corresponded to multi-component crystals (cocrystals, salts, and solvates), 60 hits. Several authors have reported pharmaceutical salts and cocrystals of FUR. A search of this dataset for drug-drug multi-component crystals revealed a total of 11 systems [8,10-13,29-31]. A common structural feature observed is the key role of the carboxylic group in the interaction with the coformer or counterion and the formation of other synthons involving the sulfonamide group that participates in stabilizing the crystal structure packing. Hence, the abundance of heterosynthons observed in the survey involving carboxylic group follows the order: carboxylic-pyridine $(54 \%)>$ carboxylic-amide $(20 \%)>$ carboxylic-imidazole $(8 \%)>$ carboxylate $\cdots$ piperazinium/carboxylate $\cdot$. ammonium/ carboxylate - . pyridinium (6\%). According to the abovementioned, the main prerequisite for the coformer selection was having the above-referred groups and being a drug. From our library of coformers, two molecules fulfil these criteria: ETZ and PRX. COSMOQuick software was used to validate our selection, predicting the tendency of cocrystal formation based on thermodynamics calculations. This tool calculates the excess enthalpy of formation $\left(\mathrm{H}_{\mathrm{ex}}\right)$ between FUR and the corresponding coformer/drug relative to the pure components in a supercooled liquid phase [32]. It requires the simplified molecular input line entry specification or SMILES of a molecule as input data. Table 2 shows COSMOQuick calculations for a list of candidates to form multi-component crystals with FUR. The list includes our two selected drugs and other coformer molecules involved in the formation of cocrystals/salts reported in the survey. Compounds with negative $\mathrm{H}_{\mathrm{ex}}$ values show an increased probability of forming cocrystals since $\mathrm{H}_{\mathrm{ex}}$ is a rough approximation of the free energy of cocrystal formation $\Delta G_{\text {cocrystal }}$. The results obtained by COSMOQuick confirm FUR preference to form cocrystals with coformers that exhibit the functional groups observed in the CSD survey, including our drug coformer candidates. 
Table 2. Ranking positions for FUR coformers reported at CSD, including the two drugs used in this study (in bold) based on COSMOQuick calculations. Non-drug molecules marked with *.

\begin{tabular}{|c|c|c|}
\hline Coformer & $\mathrm{H}_{\mathrm{ex}}(\mathrm{kcal} / \mathrm{mol})$ & $\begin{array}{l}\text { Ref. for the Corresponding } \\
\text { Cocrystal/Salt }\end{array}$ \\
\hline 1,10-phenanthroline * & -5.462215 & [33] \\
\hline 4,4'-bipyridine * & -3.87421 & [34] \\
\hline Piperazine * & -3.85138 & [9] \\
\hline Triamterene & -3.33838 & [29] \\
\hline Pentoxifylline & -3.18718 & [8] \\
\hline Cytosine * & -3.018425 & [30] \\
\hline Caffeine & -2.910815 & [30] \\
\hline Gefitinib & -2.8597 & [11] \\
\hline 4-Aminopyridine * & -2.6074 & [35] \\
\hline Urea * & -2.41366 & {$[36]$} \\
\hline Ethenzamide & -2.36084 & This work \\
\hline Erlotinib & -2.3474 & [10] \\
\hline Nicotinamide & -2.13354 & [37] \\
\hline 5-fluorocytosine & -2.101 & [12] \\
\hline 4-toluamide * & -1.95134 & [9] \\
\hline $2,2^{\prime}$-bipyridine * & -1.83637 & [33] \\
\hline 2-picolinamide * & -1.72857 & [9] \\
\hline Anthranilamide * & -1.36987 & [9] \\
\hline Piroxicam & -0.91377 & This work, [31] for acetone solvate \\
\hline
\end{tabular}

\subsection{Mechanochemical Synthesis}

Mechanochemistry has proved to be a powerful tool to obtain multi-component solid forms (salts, cocrystals, hydrates/solvates and their respective combinations), particularly in searching for new solids involving pharmaceuticals [38-41]. Cocrystallization of FUR with the corresponding coformers was carried out using various stoichiometries (1:1, 1:2, and 2:1). The patterns obtained by grinding different molar ratios of the two components were compared with the patterns of isolated API and coformers. The comparison shows that all three ratios have common characteristic peaks that were different from the two APIs. The 1:2 and 2:1 FUR:coformer patterns also contained peaks characteristics to one of the components (Figure S1, in Supplementary Materials). Only the 1:1 products had a completely different pattern where all reflections of the reagents disappeared completely, thus revealing new phases. These polycrystalline materials were used for further recrystallization to obtain suitable crystals for structure determination. In addition, there is a good agreement between the experimental and the simulated patterns (Figures S2 and S3). This synthetic approach prevented the risk for solvate formation in the case of FUR-PRX. An acetone solvate was reported previously [31] as having been obtained from acetone solution of a 1:1 stoichiometric mixture of FUR and PRX by slow evaporation.

\subsection{Structural Studies of Multi-Component Forms}

Single-crystal X-ray diffraction analysis (Table 1 and Figures S4 and S5) confirmed the cocrystal nature of FUR-ETZ and FUR-PRX obtained by LAG of the APIs in methanol.

Figure 1 shows a PXRD overlay of the ground and starting materials and the simulated pattern from the single crystal structure. This figure shows that the ground material matches the one from single crystal analysis, corresponding to FUR-ETZ cocrystal.

FUR-ETZ cocrystal crystallized in the monoclinic $P 2_{1} / c$ space group. The asymmetric unit was composed of FUR and ETZ in a 1:1 stoichiometric ratio (Figure 2a). The cocrystal adopts a ribbon structure through the acid $\cdots$ amide synthons which connect FUR catemer-like chains formed from $\mathrm{SO}_{2} \mathrm{HN}-\mathrm{H} \cdots \mathrm{O}_{\text {furan }}$ weak hydrogen bonds between neighboring FUR molecules (Figure $2 b$ ). The ribbons stack 6-membered aromatic rings of FUR and ETZ (centroid-centroid distance: 3.7262(17) $̊$ ) to form columns running along the $b$ axis (Figure 2c). These columns are reinforced by H-bonding interactions involving 
the sulfonamide and amide moieties of the cocrystal. Finally, weak $\mathrm{C}-\mathrm{H} \cdots \mathrm{O}_{\text {sulfonamide }}$ hydrogen bonds connect these columns to form the 3D structure.

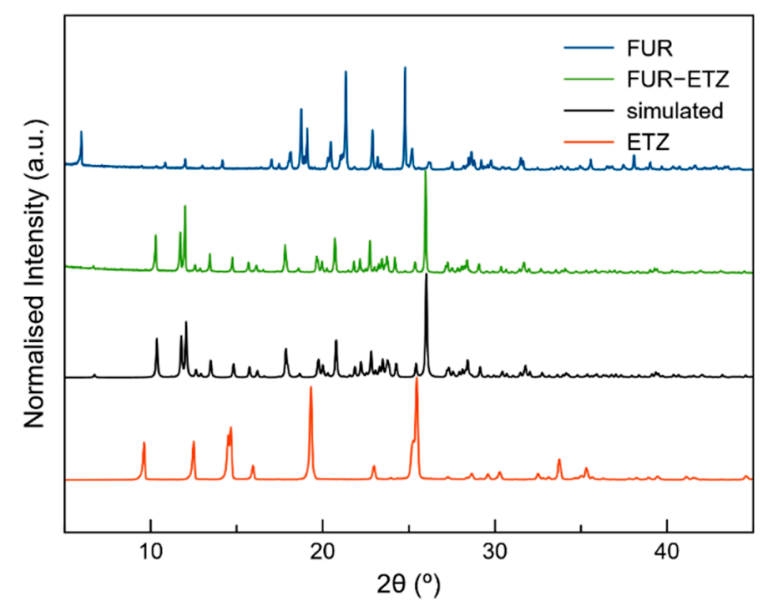

Figure 1. PXRD patterns of the new phase FUR-ETZ obtained by liquid-assisted grinding (LAG) with methanol (MET) solvent, the simulated pattern from crystal structure and the corresponding reactants.

(a)

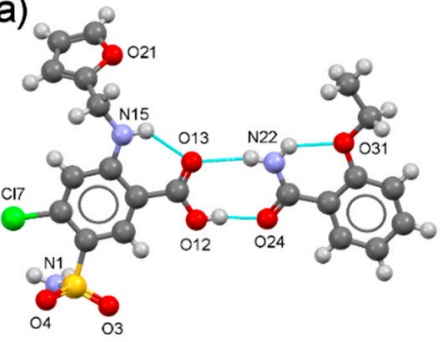

(c)

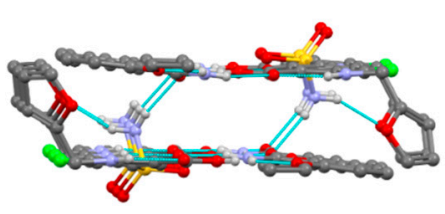

(b)
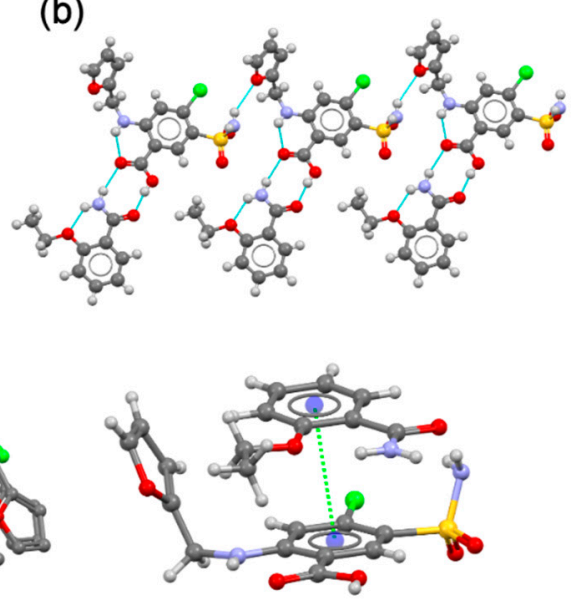

Figure 2. (a) Asymmetric unit of the FUR-ETZ cocrystal. (b) acid $\cdots$ amide and sulfonamide $\cdots$ furan synthons give a ribbon along the $b$-axis by H-bonding interactions (Table S1). (c) Left. Detail of the column structure in FUR-ETZ. Carbon bound $\mathrm{H}$ atoms omitted for clarity Right. $\pi-\pi$ stacking interaction in the FUR-ETZ cocrystal.

Figure 3 shows a PXRD overlay of the ground and starting materials, as well as the simulated patterns from the single crystal structure and the reported acetone solvate [31]. As shown in this figure, the ground material matches a new single crystal phase, corresponding to the FUR-PRX solid form.

FUR-PRX cocrystal crystallizes in the monoclinic space group $P 2_{1} / n$. The crystal structure contains one molecule each of FUR and PRX in the asymmetric unit that are associated by the heterosynthon acid $\cdots$ pyridine (Figure 4a). PRX molecules exhibits a strong intramolecular H-bonding interaction $\mathrm{O}-\mathrm{H} \cdots \mathrm{O}=\mathrm{C}$ (Table S3). FUR molecules form centrosymmetric dimers through $\mathrm{H}$-bonding interactions involving sulfonamide groups $\left(\mathrm{SO}_{2} \mathrm{HN}-\mathrm{H} \cdots \mathrm{O}=\mathrm{S}\right)$ and connect PRX molecules by additional $\mathrm{H}$-bonds $\left(\mathrm{SO}_{2} \mathrm{HN}-\mathrm{H} \cdots \mathrm{O}=\mathrm{S}\right.$ PRX) to generate ribbons running along $a$ axis. The ribbons have FUR dimers forming the backbone of the ribbon and PRX molecules in the periphery (Figure $4 \mathrm{~b}$ ). The structure is additionally stabilized by weak $\mathrm{C}-\mathrm{H} \cdots$ O hydrogen bonds formed from sulfonamide oxygen atoms with methyl groups from PRX molecules to form the 3D structure. 


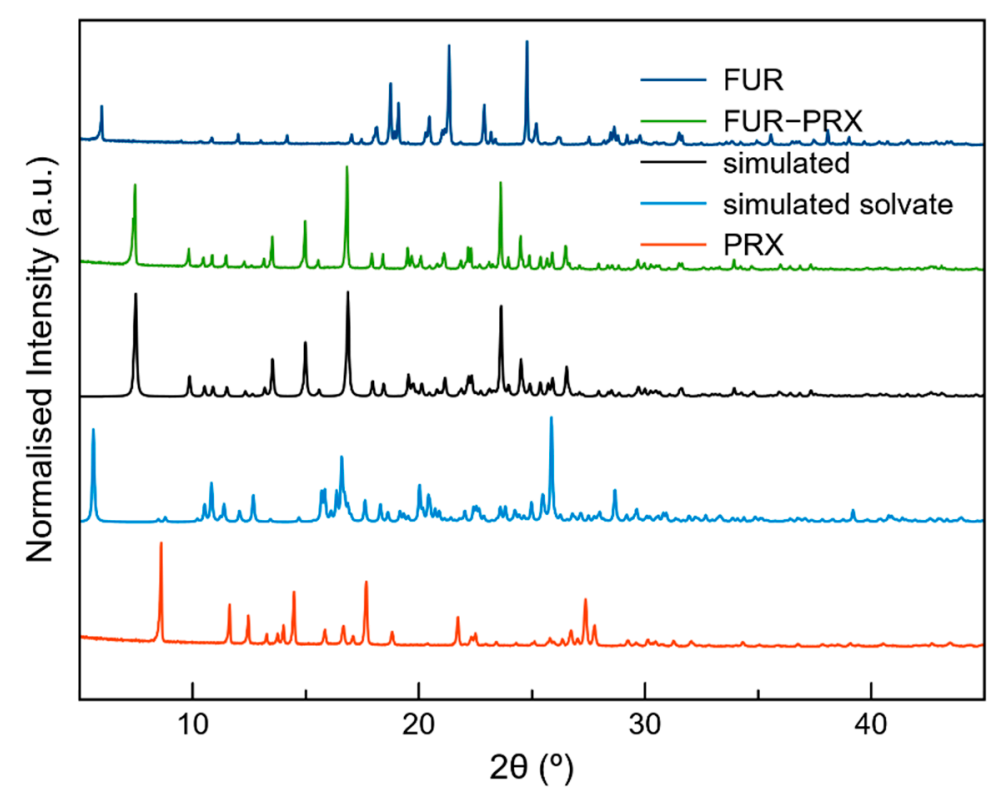

Figure 3. PXRD patterns of the new phase FUR-PRX obtained by liquid-assisted grinding (LAG) with methanol (MET) solvent, the simulated patterns from crystal structure and reported acetone solvate structure and the corresponding reactants.

(a)

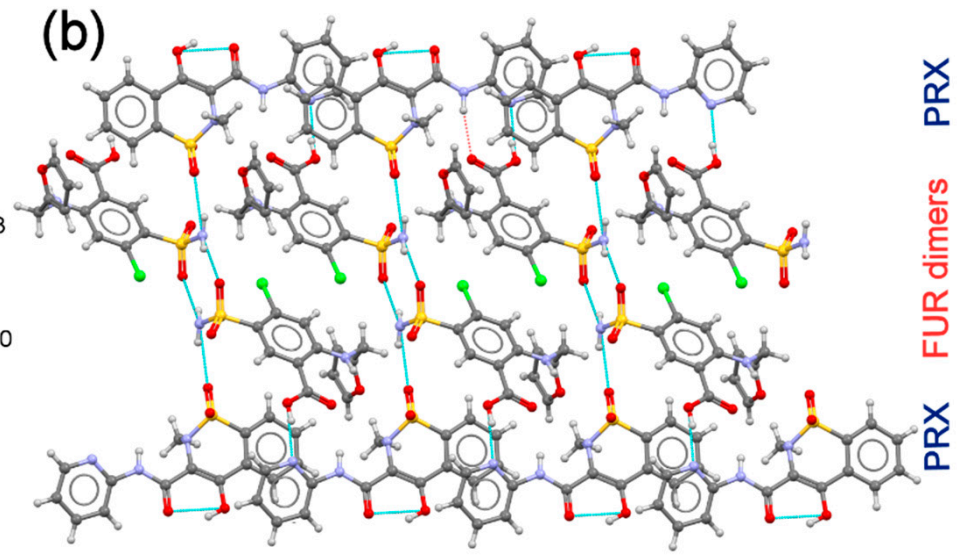

Figure 4. (a) Asymmetric unit of the FUR-PRX cocrystal. (b) Detail of the ribbon structure along the $a$ axis.

All the reported polymorphs of FUR exhibit carboxylic dimer synthons; however, each polymorph has a variation in the hydrogen bonding of sulfonamide groups giving different synthons. In the stable FUR polymorph 1 [42], a robust dimeric centrosymmetric $\mathrm{H}$-bonding interaction between sulfonamide groups is observed that further generate a linear tape structure. As expected, in both drug-drug FUR cocrystals, carboxylic dimer synthon is disrupted by the insertion of the amide or pyridine functional group for ETZ or PRX coformer, respectively. Moreover, in the case of FUR-ETZ, the sulfonamide synthon observed in the FUR polymorph 1 is replaced by two different synthons involving FUR and ETZ meanwhile in FUR-PRX, this synthon is partially maintained as sulfonamide dimer but the linear tape structure is blocked by PRX molecules. The resulting ribbon structures are different in both cocrystals and in principle would anticipate that both cocrystal will exhibit different physicochemical properties as will be discussed in the following sections.

\subsection{Fourier Transform Infrared (FT-IR) Spectroscopy}

FT-IR is a helpful technique that quickly detects the formation of novel multi-component pharmaceutical solid forms [43]. Changes in vibrational frequencies due to cocrystal/salt formation can be easily monitored. When the two APIs are joined together in the solid form, 
the reported IR bands with diagnostic values are expected to be shifted, thus indicating the presence of intermolecular forces between functional groups-i.e., hydrogen bonds-which build the cocrystal structures [44]. Band assignments (Table 3) were performed based on the crystallographic analysis (Section 3.1) and considering the spectroscopic data available for related FUR compounds found in the literature [13].

Table 3. Summary of relevant FT-IR vibrational frequencies $\left(\mathrm{cm}^{-1}\right)$ in the spectra of FUR, FUR-ETZ, and FUR-PRX.

\begin{tabular}{|c|c|c|c|c|c|}
\hline Compound & $\begin{array}{c}v\left(\mathrm{NH}_{2}\right) \\
\text { Sulfonamide }\end{array}$ & $\begin{array}{c}v(\mathrm{NH}) \\
\text { Secondary Amine }\end{array}$ & $\begin{array}{l}v(\mathrm{C}=\mathrm{O}) \\
\text { Carboxyl }\end{array}$ & $\begin{array}{c}v\left(\mathrm{COO}^{-}\right) \\
\text {Carboxylate }\end{array}$ & $\begin{array}{c}v(\mathrm{~S}=\mathrm{O}) \\
\text { Sulfonamide }\end{array}$ \\
\hline FUR & $\begin{array}{l}\text { (as) } 3400 \\
\text { (s) } 3351\end{array}$ & 3285 & 1670 & - & $\begin{array}{l}\text { (as) } 1328 \\
\text { (s) } 1139\end{array}$ \\
\hline FUR-ETZ & $\begin{array}{l}\text { (as) } 3438 \\
\text { (s) } 3291\end{array}$ & 3285 & 1670 & - & $\begin{array}{l}\text { (as) } 1339 \\
\text { (s) } 1154\end{array}$ \\
\hline FUR-PRX & $\begin{array}{l}\text { (as) } 3317 \\
\text { (s) } 3230\end{array}$ & 3269 & 1670 & - & $\begin{array}{l}\text { (as) } 1339 \\
\text { (s) } 1154\end{array}$ \\
\hline
\end{tabular}

FUR exhibits stretching frequencies at 3400 and $3351 \mathrm{~cm}^{-1}$ (sulfonamide primary amine), $3285 \mathrm{~cm}^{-1}$ (sulfonamide secondary amine), $1670 \mathrm{~cm}^{-1}$ (carboxyl stretch), and 1328 and $1139 \mathrm{~cm}^{-1}$ (sulfonamide $\mathrm{S}=\mathrm{O}$ stretching modes). The FT-IR spectra of FUR and the multi-component forms are shown in Figure 5. In FUR-ETZ and FUR-PRX cocrystals the band corresponding to carboxyl group $\left(1670 \mathrm{~cm}^{-1}\right)$ appears in the same position as in FUR. In the cocrystals, the $-\mathrm{NH}_{2}$ asymmetric and symmetric stretching modes are shifted (3438 and $3291 \mathrm{~cm}^{-1}$ for FUR-ETZ and 3317 and $3230 \mathrm{~cm}^{-1}$ for FUR-PRX). S=O stretching modes are shifted to 1345 and $1143 \mathrm{~cm}^{-1}$ in FUR-ETZ, 1339 and $1154 \mathrm{~cm}^{-1}$ in the case of FUR-PRX, confirming that these functional groups interact with the coformer, as demonstrated in the crystal structures analysis. The FT-IR vibrational frequency comparisons are summarized in Table 3.

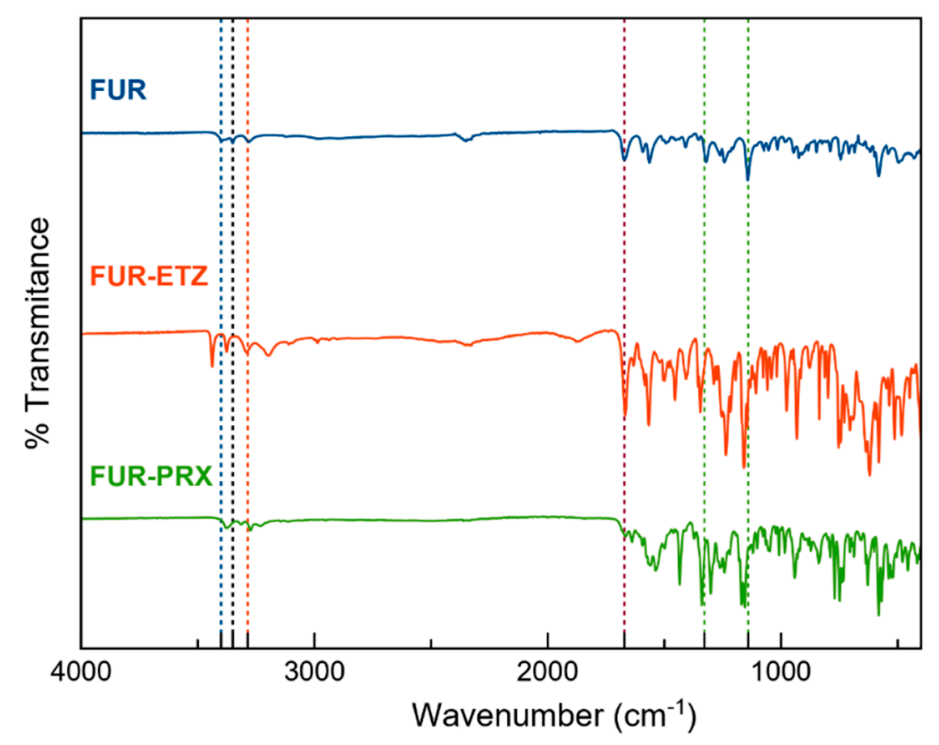

Figure 5. Comparison of Fourier transform infrared (FT-IR) spectra of FUR, FUR-ETZ and FUR-PRX solid forms.

\subsection{Thermal Analysis}

It is well accepted that the melting point of an API can be altered through cocrystallization [45]. The outcome will generally be a solid with a melting point between (M), lower $(\mathrm{L})$, or higher $(\mathrm{H})$ than the isolated API and coformer, following the occurrence trend $\mathrm{M}>>\mathrm{L}>\mathrm{H}$ [46]. The thermal behavior of the reported compounds was studied by DSC. In Figure 6, the DSC of the corresponding FUR-ETZ and FUR-PRX cocrystals are reported. Each trace shows one single endothermic event, which represents the melting point of these 
pure species. Interestingly, while the melting point of the FUR-ETZ cocrystal $\left(187.67^{\circ} \mathrm{C}\right)$ is in between those of the reported for the two reference APIs (ETZ: $129-134{ }^{\circ} \mathrm{C}$; FUR: 203-205 ${ }^{\circ} \mathrm{C}$ ), FUR-PRX cocrystal shows a melting endotherm at $214.82{ }^{\circ} \mathrm{C}$, higher than the melting point of its components (PRX: $201.89{ }^{\circ} \mathrm{C}$; FUR: $203-205^{\circ} \mathrm{C}$ ), an indication that this pharmaceutical cocrystal is thermally more stable than FUR by itself. Although the density and packing coefficient of the cocrystals are similar (Table 1), the overall packing arrangement of FUR-PRX and the non-covalent interactions involved impact its thermal behavior.

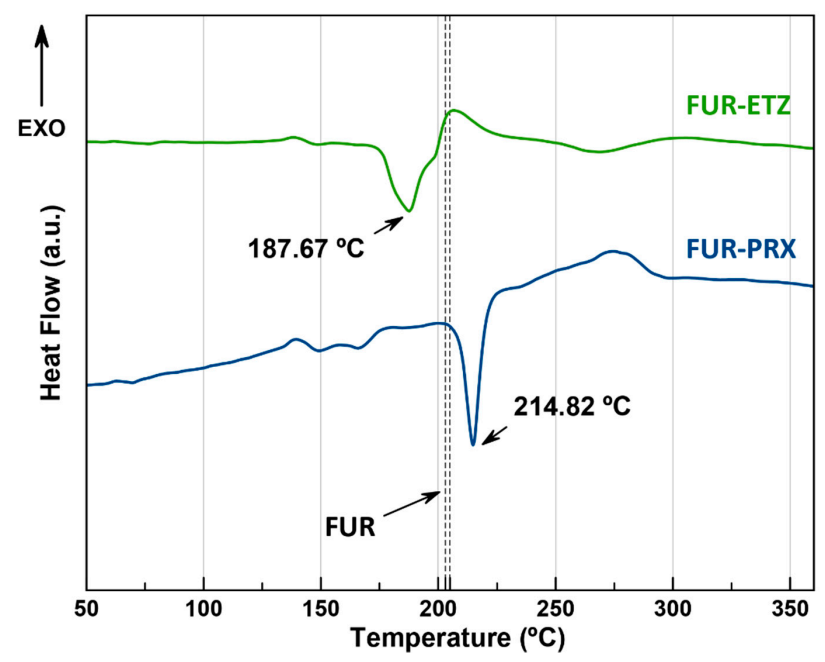

Figure 6. Differential scanning calorimetry (DSC) plots of FUR-ETZ and FUR-PRX. Dotted lines correspond to the range of temperature reported for melting of FUR.

\subsection{Stability Studies}

The stability of cocrystals was studied in this work by performing aqueous slurry experiments at $25^{\circ} \mathrm{C}$ and storing them at accelerated ageing conditions $\left(40{ }^{\circ} \mathrm{C}\right.$ and $75 \%$ relative humidity). The thermodynamic stability of cocrystals was first evaluated by slurry experiments at $25^{\circ} \mathrm{C}$. In these experiments, excess solids of the cocrystal powders were stirred in deionized water for $24 \mathrm{~h}$. The resulting filtered and air-dried samples were analyzed by PXRD to evaluate their phase purity, and it was observed that the two cocrystals were stable upon slurrying. These observations suggest that the cocrystals are thermodynamically stable at room temperature. Likewise, results of the stability tests suggest that the two new solid forms remained the same after storage for two months (Figure 7). The stability of the cocrystals at accelerated test conditions is consistent with the thermodynamic stability observed in the slurry experiments.

(a)

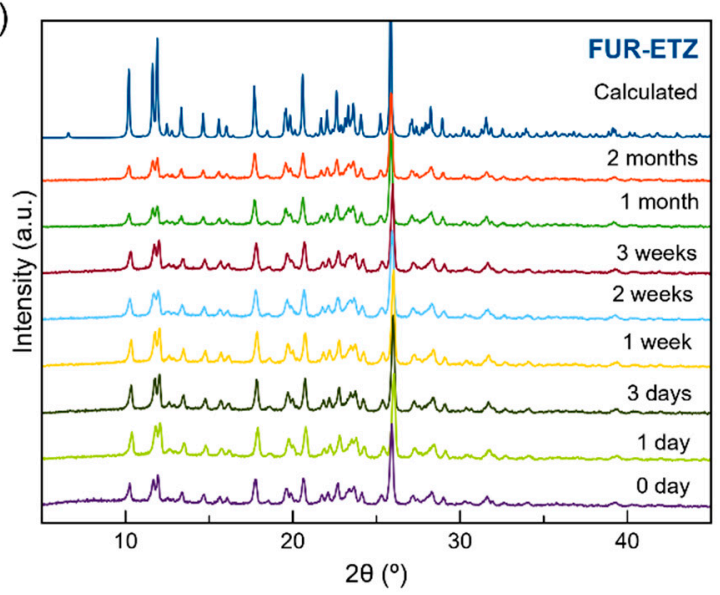

(b)

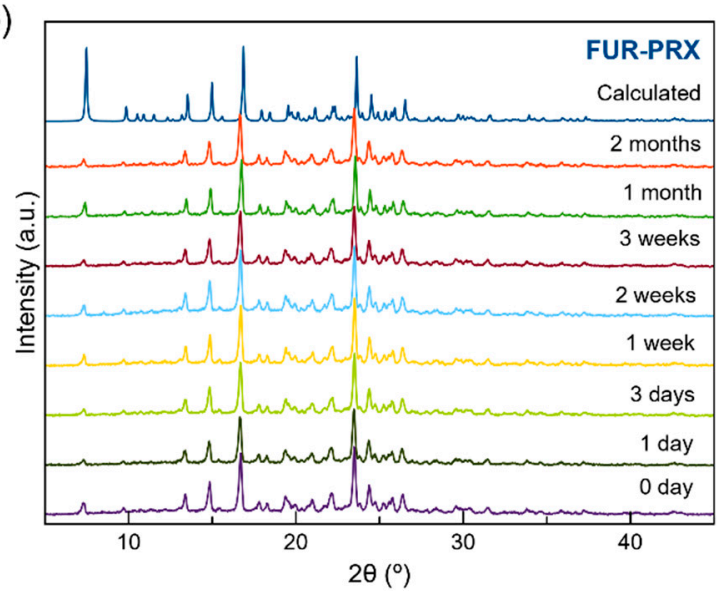

Figure 7. PXRD patterns of FUR-ETZ (a) and FUR-PRX (b) with respect to the stability under accelerated ageing conditions $\left(40{ }^{\circ} \mathrm{C}, 75 \% \mathrm{RH}\right)$ at different time intervals. 


\subsection{Equilibrium Solubility}

As observed in the previous section, cocrystals were thermodynamically stable when suspended in water at room temperature. They did not transform to component phases or there is no evidence of phase transitions, suggesting that these phases have equal or lower solubility than the drug or coformer. The equilibrium solubility of the new FUR cocrystals was lower than that of FUR at pH 7.4. As seen in Table 4, cocrystals possess lower solubility than FUR. Although the differences in equilibrium solubility between FUR and the cocrystals were significant, interestingly, the extent of enhanced solubility of the multi-component solids is more significant than the solubility of the drug coformers.

Table 4. Equilibrium solubility of FUR and its cocrystals in water PBS pH 7.4.

\begin{tabular}{cccc}
\hline Solid Form & $\begin{array}{c}\text { Equilibrium Solubility at } \\
\mathbf{2 5}{ }^{\circ} \mathbf{C}(\mathbf{m g} / \mathbf{m L})\end{array}$ & $\begin{array}{c}\text { Extent of Increase Relative to } \\
\text { the Solubility of FUR. }\end{array}$ & $\begin{array}{c}\text { Extent of Increase Relative to } \\
\text { the Solubility of Coformer. }\end{array}$ \\
\hline FUR & 2.40 & - & - \\
FUR-ETZ & 1.24 & $\times 0.52$ & $\times 41(\mathrm{ETZ})^{\mathrm{a}}$ \\
FUR-PRX & 1.47 & $\times 0.61$ & $\times 84(\mathrm{PRX})^{\mathrm{b}}$ \\
\hline
\end{tabular}

${ }^{\text {a }}$ Reported solubility of ETZ at $27^{\circ} \mathrm{C}: 0.03 \mathrm{mg} / \mathrm{mL}$ [47]. ${ }^{\mathrm{b}}$ Reported solubility of PRX at $37^{\circ} \mathrm{C}: 0.0198 \mathrm{mg} / \mathrm{mL}$ [48].

\section{Conclusions}

In conclusion, we have described two new drug-drug cocrystals containing FUR and ETZ and PRX as coformers. A mechanochemical synthetic route have allowed to avoid hydrate/solvate formation as evidenced in the case of FUR-PRX. Expected hydrogen bonds contributed by the drug coformers sustain the cocrystals, disrupting the acid:aciddimer synthon observed in the stable FUR polymorph 1. All the solids exhibit good thermal stability, and good stability under accelerated ageing. Although they do not exhibit increased solubility than FUR drug, the drug coformers notably do. However, the success of these drug-drug cocrystals as potential fixed-dose solids requires an appropriately designed clinical study to establish their safety and effectiveness.

Supplementary Materials: The following are available online at https:/ / www.mdpi.com/article/10.339 0/cryst11111339/s1, Figure S1. PXRD patterns of FUR-ETZ obtained by grinding the two components at different molar ratios. Blue dotted lines indicate characteristic FUR reflections. Orange dotted lines indicate characteristic ETZ reflections; Figure S2. PXRD patterns of FUR-PRX obtained by grinding the two components at different molar ratios. Blue dotted lines indicate characteristic FUR reflections. Orange dotted lines indicate characteristic PRX reflections; Figure S3. Le bail profile fit (red line) to the experimental PXRD data (blue line) of FUR-ETZ (a) and FUR-PRX (b). The profile fitting for both the cocrystals shows low discrepancy (grey line); Figure S4. ORTEP representation showing the asymmetric unit of FUR-ETZ with atom numbering scheme (thermal ellipsoids are plotted with the 50\% probability level); Figure S5. ORTEP representation showing the asymmetric unit of FUR-PRX with atom numbering scheme (thermal ellipsoids are plotted with the $50 \%$ probability level); Figure S6. TGA traces of FUR-ETZ (top) and FUR-PRX (bottom); Figure S7. Solubility curve of FUR-ETZ in water PBS at pH 7.4; Figure S8. Solubility curve of FUR-PRX in water PBS at pH 7.4; Figure S9. PXRD patterns of FUR-ETZ after the stability slurry assay (at $25^{\circ} \mathrm{C}$, during $24 \mathrm{~h}$, in water); Figure S10. PXRD patterns of FUR-PRX after the stability slurry assay (at $25^{\circ} \mathrm{C}$, during $24 \mathrm{~h}$, in water); Table S1. Hydrogen bonds for FUR-ETZ ( $\AA$ and deg.); Table S2. $\pi, \pi$-stacking interactions analysis of compound FUR—ETZ. Table S3. Hydrogen bonds for FUR—PRX ( $\AA$ and deg.).

Author Contributions: Conceptualization and methodology, D.C.-L.; Formal analysis and investigation, C.A.-P., L.R.-D., F.J.A.-M., A.D.-M. and J.G.-M.; Writing-original draft preparation, D.C.-L.; Writing-review and editing, D.C.-L.; Funding acquisition, D.C.-L. and J.G.-M.; Supervision, D.C.-L. All authors have read and agreed to the published version of the manuscript.

Funding: This research was funded by Spanish Agencia Estatal de Investigación of the Ministerio de Ciencia, Innovación y Universidades (MICIU) and co-funded with FEDER, UE, Project No. PGC2018102047-B-I00 (MCIU/AEI/FEDER, UE) and Project No. B-FQM-478-UGR20 (FEDER-Universidad de Granada, Spain). 
Institutional Review Board Statement: Not applicable.

Informed Consent Statement: Not applicable.

Data Availability Statement: Not applicable.

Acknowledgments: F.J.A.-M. wants to acknowledge an FPI grant (ref. PRE2019-088832).

Conflicts of Interest: The authors declare no conflict of interest.

\section{References}

1. Jackson, E.K. Diuretics. In Goodman and Gilman's The Pharmacological Basis of Therapeutics; Brunton, L., Lazo, J., Parker, K., Eds.; McGraw-Hill: New York, NY, USA, 2006; pp. 737-770. ISBN 0071422803.

2. Carone, L.; Oxberry, S.G.; Twycross, R.; Charlesworth, S.; Mihalyo, M.; Wilcock, A. Furosemide. J. Pain Symptom Manag. 2016, 52, 144-150. [CrossRef]

3. Amidon, G.L.; Lennernäs, H.; Shah, V.P.; Crison, J.R. A Theoretical Basis for a Biopharmaceutic Drug Classification: The Correlation of in Vitro Drug Product Dissolution and in Vivo Bioavailability. Pharm. Res. 1995, 12, 413-420. [CrossRef]

4. Wisher, D. Martindale: The Complete Drug Reference. 37th Ed. J. Med Libr. Assoc. JMLA 2012, 100, 75-76. [CrossRef]

5. Grahnén, A.; Hammarlund, M.; Lundqvist, T. Implications of Intraindividual Variability in Bioavailability Studies of Furosemide. Eur. J. Clin. Pharmacol. 1984, 27, 595-602. [CrossRef]

6. Berry, D.J.; Steed, J.W. Pharmaceutical Cocrystals, Salts and Multicomponent Systems; Intermolecular Interactions and Property Based Design. Adv. Drug Deliv. Rev. 2017, 117, 3-24. [CrossRef] [PubMed]

7. Kumar, A.; Kumar, S.; Nanda, A. A Review about Regulatory Status and Recent Patents of Pharmaceutical Co-Crystals. Adv. Pharm. Bull. 2018, 8, 355-363. [CrossRef]

8. Stepanovs, D.; Mishnev, A. Multicomponent Pharmaceutical Cocrystals: Furosemide and Pentoxifylline. Acta Crystallogr. Sect. C Cryst. Struct. Commun. 2012, 68, o488-o491. [CrossRef] [PubMed]

9. Banik, M.; Gopi, S.P.; Ganguly, S.; Desiraju, G.R. Cocrystal and Salt Forms of Furosemide: Solubility and Diffusion Variations. Cryst. Growth Des. 2016, 16, 5418-5428. [CrossRef]

10. George, C.P.; Thorat, S.H.; Shaligram, P.S.; Suresha, P.R.; Gonnade, R.G. Drug-Drug Cocrystals of Anticancer Drugs ErlotinibFurosemide and Gefitinib-Mefenamic Acid for Alternative Multi-Drug Treatment. CrystEngComm 2020, 22, 6137-6151. [CrossRef]

11. Thorat, S.H.; Sahu, S.K.; Patwadkar, M.V.; Badiger, M.V.; Gonnade, R.G. Drug-Drug Molecular Salt Hydrate of an Anticancer Drug Gefitinib and a Loop Diuretic Drug Furosemide: An Alternative for Multidrug Treatment. J. Pharm. Sci. 2015, 104, 4207-4216. [CrossRef] [PubMed]

12. Diniz, L.F.; Carvalho, P.S.; Pena, S.A.C.; Gonçalves, J.E.; Souza, M.A.C.; de Souza Filho, J.D.; Bomfim Filho, L.F.O.; Franco, C.H.J.; Diniz, R.; Fernandes, C. Enhancing the Solubility and Permeability of the Diuretic Drug Furosemide via Multicomponent Crystal Forms. Int. J. Pharm. 2020, 587, 119694. [CrossRef] [PubMed]

13. Abraham Miranda, J.; Garnero, C.; Chattah, A.K.; Santiago De Oliveira, Y.; Ayala, A.P.; Longhi, M.R. Furosemide:Triethanolamine Salt as a Strategy to Improve the Biopharmaceutical Properties and Photostability of the Drug. Cryst. Growth Des. 2019, 19, 2060-2068. [CrossRef]

14. Wang, X.; Du, S.; Zhang, R.; Jia, X.; Yang, T.; Zhang, X. Drug-Drug Cocrystals: Opportunities and Challenges. Asian J. Pharm. Sci. 2021, 16, 307-317. [CrossRef]

15. Herchuelz, A.; Derenne, F.; Deger, F.; Juvent, M.; van Ganse, E.; Staroukine, M.; Verniory, A.; Boeynaems, J.M.; Douchamps, J. Interaction between Nonsteroidal Anti-Inflammatory Drugs and Loop Diuretics: Modulation by Sodium Balance. J. Pharmacol. Exp. Ther. 1989, 248, 1175-1181.

16. Paterson, C.A.; Jacobs, D.; Rasmussen, S.; Youngberg, S.P.; McGuinness, N. Randomized, Open-Label, 5-Way Crossover Study to Evaluate the Pharmacokinetic/Pharmacodynamic Interaction between Furosemide and the Non-Steroidal Anti-Inflammatory Drugs Diclofenac and Ibuprofen in Healthy Volunteers. Int. J. Clin. Pharmacol. Ther. 2011, 49, 477-490. [CrossRef]

17. Moore, N.; Pollack, C.; Butkerait, P. Adverse Drug Reactions and Drug-Drug Interactions with over-the-Counter NSAIDs. Ther Clin Risk Manag. 2015, 11, 1061-1075. [CrossRef]

18. Baker, D.E. Piroxicam-Furosemide Drug Interaction. Drug Intell. Clin. Pharm. 1988, 22, 505-506. [CrossRef] [PubMed]

19. Allen, F.H. The Cambridge Structural Database: A Quarter of a Million Crystal Structures and Rising. Acta Crystallogr. Sect. B Struct. Sci. 2002, 58, 380-388. [CrossRef] [PubMed]

20. Loschen, C.; Klamt, A. Solubility Prediction, Solvate and Cocrystal Screening as Tools for Rational Crystal Engineering. J. Pharm. Pharmacol. 2015, 67, 803-811. [CrossRef]

21. Coelho, A.A. TOPAS and TOPAS-Academic: An Optimization Program Integrating Computer Algebra and Crystallographic Objects Written in C++: An. J. Appl. Crystallogr. 2018, 51, 210-218. [CrossRef]

22. Bruker APEX3. APEX3 V2019.1; Bruker-AXS: Madison, WI, USA, 2019.

23. Sheldrick, G.M. SHELXT-Integrated Space-Group and Crystal-Structure Determination. Acta Crystallogr. Sect. A Found. Crystallogr. 2015, 71, 3-8. [CrossRef] [PubMed]

24. Sheldrick, G.M. Crystal Structure Refinement with SHELXL. Acta Crystallogr. Sect. C Struct. Chem. 2015, 71, 3-8. [CrossRef] 
25. Dolomanov, O.V.; Bourhis, L.J.; Gildea, R.J.; Howard, J.A.K.; Puschmann, H. OLEX2: A Complete Structure Solution, Refinement and Analysis Program. J. Appl. Crystallogr. 2009, 42, 339-341. [CrossRef]

26. Spek, A.L. Structure Validation in Chemical Crystallography. Acta Crystallogr. Sect. D Biol. Crystallogr. 2009, 65, 148-155. [CrossRef]

27. Macrae, C.F.; Bruno, I.J.; Chisholm, J.A.; Edgington, P.R.; McCabe, P.; Pidcock, E.; Rodriguez-Monge, L.; Taylor, R.; van de Streek, J.; Wood, P.A. Mercury CSD 2.0-New Features for the Visualization and Investigation of Crystal Structures. J. Appl. Crystallogr. 2008, 41, 466-470. [CrossRef]

28. Horst, J.H.T.; Deij, M.A.; Cains, P.W. Discovering New Co-Crystals. Cryst. Growth Des. 2009, 9. [CrossRef]

29. Peng, B.; Wang, J.R.; Mei, X. Triamterene-Furosemide Salt: Structural Aspects and Physicochemical Evaluation. Acta Crystallogr. Sect. B: Struct. Sci. Cryst. Eng. Mater. 2018, 74, 738-741. [CrossRef]

30. Goud, N.R.; Gangavaram, S.; Suresh, K.; Pal, S.; Manjunatha, S.G.; Nambiar, S.; Nangia, A. Novel Furosemide Cocrystals and Selection of High Solubility Drug Forms. J. Pharm. Sci. 2012, 101, 664-680. [CrossRef]

31. Mishnev, A.; Kiselovs, G. New Crystalline Forms of Piroxicam. Z. Fur Nat.-Sect. C J. Biosci. 2013, 68 B, 168-174. [CrossRef]

32. Abramov, Y.A.; Loschen, C.; Klamt, A. Rational Coformer or Solvent Selection for Pharmaceutical Cocrystallization or Desolvation. J. Pharm. Sci. 2012, 101, 3687-3697. [CrossRef] [PubMed]

33. Sangtani, E.; Mandal, S.K.; Sreelakshmi, A.S.; Munshi, P.; Gonnade, R.G. Salts and Cocrystals of Furosemide with Pyridines: Differences in $\pi$-Stacking and Color Polymorphism. Cryst. Growth Des. 2017, 17, 3071-3087. [CrossRef]

34. Srirambhatla, V.K.; Kraft, A.; Watt, S.; Powell, A.V. A Robust Two-Dimensional Hydrogen-Bonded Network for the Predictable Assembly of Ternary Co-Crystals of Furosemide. CrystEngComm 2014, 16, 9979-9982. [CrossRef]

35. Sangtani, E.; Sahu, S.K.; Thorat, S.H.; Gawade, R.L.; Jha, K.K.; Munshi, P.; Gonnade, R.G. Furosemide Cocrystals with Pyridines: An Interesting Case of Color Cocrystal Polymorphism. Cryst. Growth Des. 2015, 15, 5858-5872. [CrossRef]

36. Rahal, O.; Majumder, M.; Spillman, M.J.; van de Streek, J.; Shankland, K. Co-Crystal Structures of Furosemide:Urea and Carbamazepine:Indomethacin Determined from Powder x-Ray Diffraction Data. Crystals 2020, 10, 42. [CrossRef]

37. Ueto, T.; Takata, N.; Muroyama, N.; Nedu, A.; Sasaki, A.; Tanida, S.; Terada, K. Polymorphs and a Hydrate of FurosemideNicotinamide 1:1 Cocrystal. Cryst. Growth Des. 2012, 12, 485-494. [CrossRef]

38. Braga, D.; Maini, L.; Grepioni, F. Mechanochemical Preparation of Co-Crystals. Chem. Soc. Rev. 2013, 42, 7638-7648. [CrossRef]

39. Delori, A.; Friščić, T.; Jones, W. The Role of Mechanochemistry and Supramolecular Design in the Development of Pharmaceutical Materials. CrystEngComm 2012, 14, 2350. [CrossRef]

40. Friščić, T.; Childs, S.L.; Rizvi, S.A.A.; Jones, W. The Role of Solvent in Mechanochemical and Sonochemical Cocrystal Formation: A Solubility-Based Approach for Predicting Cocrystallisation Outcome. CrystEngComm 2009, 11, 418-426. [CrossRef]

41. Verdugo-Escamilla, C.; Alarcón-Payer, C.; Frontera, A.; Acebedo-Martínez, F.J.; Domínguez-Martín, A.; Gómez-Morales, J.; Choquesillo-Lazarte, D. Interconvertible Hydrochlorothiazide-Caffeine Multicomponent Pharmaceutical Materials: A Solvent Issue. Crystals 2020, 10, 1088. [CrossRef]

42. Babu, N.J.; Cherukuvada, S.; Thakuria, R.; Nangia, A. Conformational and Synthon Polymorphism in Furosemide (Lasix). Cryst. Growth Des. 2010, 10, 1979-1989. [CrossRef]

43. Heinz, A.; Strachan, C.J.; Gordon, K.C.; Rades, T. Analysis of Solid-State Transformations of Pharmaceutical Compounds Using Vibrational Spectroscopy. J. Pharm. Pharmacol. 2009, 61, 971-988. [CrossRef] [PubMed]

44. Mukherjee, A.; Tothadi, S.; Chakraborty, S.; Ganguly, S.; Desiraju, G.R. Synthon Identification in Co-Crystals and Polymorphs with IR Spectroscopy. Primary Amides as a Case Study. CrystEngComm 2013, 15, 4640-4654. [CrossRef]

45. Schultheiss, N.; Newman, A. Pharmaceutical Cocrystals and Their Physicochemical Properties. Cryst. Growth Des. 2009, 9, 2950-2967. [CrossRef] [PubMed]

46. Perlovich, G. Melting Points of One- and Two-Component Molecular Crystals as Effective Characteristics for Rational Design of Pharmaceutical Systems. Acta Crystallogr. Sect. B Struct. Sci. Cryst. Eng. Mater. 2020, 76, 696-706. [CrossRef]

47. Khatioda, R.; Bora, P.; Sarma, B. Trimorphic Ethenzamide Cocrystal: In Vitro Solubility and Membrane Efflux Studies. Cryst. Growth Des. 2018, 18, 4637-4645. [CrossRef]

48. Karataş, A.; Yüksel, N.; Baykara, T. Improved Solubility and Dissolution Rate of Piroxicam Using Gelucire 44/14 and Labrasol. Farmaco 2005, 60, 777-782. [CrossRef] 